\title{
Value of urban green spaces in promoting healthy living and wellbeing: prospects for planning
}

This article was published in the following Dove Press journal:

Risk Management and Healthcare Policy

27 August 2015

Number of times this article has been viewed

\author{
Andrew Chee Keng Lee' \\ Hannah C Jordan' \\ Jason Horsley ${ }^{2}$ \\ 'Section of Public Health, School \\ of Health and Related Research, \\ University of Sheffield, ${ }^{2}$ Sheffield City \\ Council, Sheffield, UK
}

\begin{abstract}
There has been considerable work done in recent years exploring the value of urban green space for health and wellbeing. Urban green spaces provide environmental benefits through their effects on negating urban heat, offsetting greenhouse gas emissions, and attenuating storm water. They also have direct health benefits by providing urban residents spaces for physical activity and social interaction, and allowing psychological restoration to take place. Consequently, there is a real need to understand the mechanisms by which these benefits accrue. Previously, much of the focus has been on the characteristics of the urban green space that are likely to influence its use, such as its accessibility, quality, facilities, attractiveness, and security. This assumes a causal relationship, when in reality the relationship is more complex and multifactorial. It is more likely that it is the functionality of the green space, be it for exercise or sociocultural activities, rather than its character, which translates to the reported benefits. Challenges exist, such as competing urban planning priorities, economic considerations, and market forces. There is thus a need for urban planning to match the health benefits sought with the needs of the community and the functionality that the urban green space will serve.
\end{abstract}

Keywords: urban green space, public open space, urban planning, public health

\section{Introduction}

Globally, the epidemics of obesity and mental illness affecting populations in many developed and developing countries are worsening around the world. Worryingly, obesity rates are on the rise, with figures as high as a quarter of the adult population in England and a third of adults in the USA affected. ${ }^{1,2}$ Similarly, the annual prevalence of mental illness is high, with conditions such as depression affecting approximately one in 20 of the population. ${ }^{3}$ Both of these public health issues are products of contemporary lifestyles in an increasingly urbanized world, and greater understanding of the determinants of urban health will become increasingly important for policy makers.

These two public health issues have traditionally been seen as the remit of health professionals and health care providers. However, in recent decades, there has been a growing awareness of the possible value of urban planning interventions in addressing them. ${ }^{4}$ For example, some of the mental health issues arising in contemporary society and physical health challenges resulting from modern diets and sedentary lifestyles can be tackled through various activities undertaken in green environments. ${ }^{5}$ Research into urban green space has grown considerably, particularly regarding its potential health benefits as well as approaches to optimizing them.

We provide here a narrative summary of the published literature on urban green space. We broadly define urban green space as any "green space”, "public open space”, 
or "park" in an urban setting. While there may be subtle qualitative differences between these settings, we have used the terms synonymously for the purpose of this review.

\section{Green spaces, urban planning, and design}

The utility of urban green spaces for urban planners can be seen through many lenses. ${ }^{6}$ Urban green spaces fulfil a range of different roles, such as social spaces and areas for recreation and cultural purposes. They also have economic and environmental purposes. Indeed, urban greening projects have been undertaken to maintain and increase property values due to their esthetic characteristics and functionality. ${ }^{7}$

Conversely, neighborhood environmental decay in rundown areas negatively affects residents' sense of security and heightens perceptions (and possibly the incidence) of crime. One US study suggests that urban greening may counteract this. ${ }^{8}$ There were observed reductions in gun crime and vandalism following the greening of vacant urban land. Residents reported feeling less stressed as a result. There was also an increase in physical activity, which may have been due to residents being more inclined to exercise in a cleaner, greener, and "safer" environment.

The other key value of urban green spaces are the environmental benefits they provide. ${ }^{7,9}$ For example, they counteract the urban heat island effect, thereby reducing the energy costs of cooling buildings. Urban greenery minimizes air, water, and noise pollution, and may offset greenhouse gas emissions through $\mathrm{CO}_{2}$ absorption. ${ }^{10}$ Urban greenery also provides storm water attenuation, thereby acting as a measure for flood mitigation. ${ }^{11}$ Further ecological benefits include preservation of biodiversity and nature conservation. ${ }^{12}$ Consequently, due to the range of environmental services they afford, urban green spaces can be viewed as a public good.

From the health perspective, urban green spaces are spaces that allow for health-promoting activities, such as physical activity or rest and relaxation, to take place. In this way, they have a direct relationship with the quality of life of urban dwellers. The range of purported health benefits of urban green spaces is considerable and this is covered in the following section.

\section{Links to exercise, mental health, and overall wellbeing}

Numerous studies in the past decade have reported the association between contact with green spaces and health benefits both at the individual and population level. ${ }^{13,14}$
These have included beneficial associations with health outcomes, such as cardiovascular and respiratory mortality. ${ }^{15}$ The three main hypothesized mechanisms for these benefits include: provision of opportunities for physical activity, recovery from stress and attention fatigue, and facilitation of social contact.

\section{Physical activity/exercise}

There is a growing body of evidence indicating that physical activity levels may be influenced by the urban environment. Studies have found associations between availability of urban green space and physical activity levels. ${ }^{16}$ The provision of urban green spaces such as parks provides an important place for people to be active. ${ }^{17}$ A significant proportion of vigorous physical activity in childhood takes place in urban parks. ${ }^{18}$ Urban green space is therefore particularly important in urban areas where access to the open countryside is limited. ${ }^{19}$ Indeed, accessibility of green spaces influences not just the likelihood of physical activity being undertaken but also its frequency. ${ }^{20}$ It is also linked to a lower likelihood of being overweight or obese. Green spaces therefore may help facilitate active lifestyles in the urban setting. ${ }^{21}$ In addition, they may be used as therapeutic spaces for rehabilitative exercise, such as for persons with coronary artery disease, ${ }^{22}$ and have been associated with lower rates of diseases such as type 2 diabetes mellitus. ${ }^{23}$

\section{Mental health and wellbeing}

Urban green space may provide residents with opportunities for contact with the natural environment. Such contact has positive restorative effects on mental health and wellbeing and may also help to provide a buffer against stressful life events. ${ }^{24,25}$ The benefits of green space on mental health and wellbeing may also arise from participation in activities occurring in these spaces, such as social interaction or physical exercise. ${ }^{26}$ These benefits include alleviation of stress and anxiety, and improved mood and attention.

\section{Social contact}

As noted earlier, urban green spaces also provide opportunities for social interactions to take place. This in turn could help reduce social isolation, generate social capital, and lead to greater personal resilience and wellbeing. ${ }^{7}$ This seems to be particularly important for elderly population groups. ${ }^{27,28}$ Interestingly, in a few studies, social factors (eg, neighborliness) had a greater influence on the frequency of use of urban parks than the physical features of the parks. ${ }^{29,30}$ 


\section{When, why, and how do people use green spaces?}

It is important to understand the user's intended purpose for going to a green space. These are unsurprisingly varied. It is often a venue for exercise and physical activity either on an individual or group basis. In addition, some users may use the green space for a secondary purpose, such as a transport route to another location. ${ }^{31}$

Other uses of green spaces identified from previous studies include relaxation and stress reduction, to obtain peace and quiet, or to experience nature. Studies have also observed that people use green spaces for rest and restoration and as means to de-stress. ${ }^{32,33}$ Green spaces perceived to be "serene", "social", and "natural" were said to have greater restorative effects. One meta-analysis reported that exercise undertaken in all green environments improved both self-esteem and mood. It also suggested that the presence of a water feature in a green space improved these positive effects. ${ }^{5}$

Urban green spaces are also used as places where social interaction occurs. ${ }^{29,32}$ One ethnographic study from Scotland observed that green space had different "social" meanings and understandings for different user groups. This in turn shaped how people "used" green spaces and facilitated different types of social interaction. Conversely, different types of green space facilitate different kinds of interactions between people. Regular social interaction by park users, eg, could form the basis of greater community ties, foster a sense of identity and belonging, and generate more social capital. ${ }^{34}$

It is important to recognize that not all users see green spaces in the same way. Studies have shown that there is an implied "correct" way to use green space, specifically for an appreciation of nature, quiet contemplation, and gentle recreation. ${ }^{35}$ Users who perceive the green spaces as a "playground", who value the entertainment opportunities, cafes, organized events, and facilities can be seen as in conflict with these ideas. ${ }^{32}$ An appreciation of the variety of ways in which people use green spaces is therefore vital for effective planning.

\section{Determinants of use of public green spaces}

The determinants of use of public green spaces are also complex, interconnected, and varied. ${ }^{28}$ The availability of urban green space is first and foremost a key requirement. ${ }^{36}$ There is some suggestion that size matters, with greater benefits associated with larger green spaces. ${ }^{14}$ The size of the urban green space may also dictate how it is used, in that larger spaces may be more likely to be used for physical activity, while smaller spaces are primarily used for "socializing" and "rest and restitution". ${ }^{2}$

Another key determinant for use of green spaces, cited in numerous studies, is their accessibility. ${ }^{7}$ This includes the distance from home, in that persons living in close proximity to a green space are more likely to use it and to do so more frequently. ${ }^{37}$ The optimal distance has been said to be less than $0.5 \mathrm{~km}$ or 5 minutes' walking time. Ease of accessibility is also important, such as the presence of cycle paths and minimal obstruction (eg, no need to cross busy roads). A survey of the use of green space in Odense, Denmark, showed that in $46 \%$ of the respondents the green space people used most was often not the closest one to them. They also found that self-reported poor health, having a child under 6 years, or having a dog made people significantly more likely to use their nearest green space. ${ }^{31}$

The qualities and characteristics of the urban green space are likely to be important as well. ${ }^{36}$ In addition to factors such as distance to the green space, formal green spaces are more likely to be used. This is probably because such areas tend to have features that facilitate physical activity, such as good path networks and a perception of safety. ${ }^{20}$ Other studies have also reported how both the presence of environmental features and residents' subjective awareness of those features are important in influencing behavior change..$^{21,30}$

Perceptions of environmental hygiene, security, and safety are other important features. Rundown public open spaces may often be associated with unsavory activities, such as illegal gambling, homelessness, and prostitution, as well as crime and vandalism. ${ }^{29}$ Such associations may deter key user groups, especially women and children, as well as the elderly. ${ }^{37}$

One study from Australia found that the quality of the space was more important than quantity on likelihood of psychological distress. ${ }^{38}$ Quality was described as the presence of walking paths, shade, water features, irrigated lawns, birdlife, lighting, sporting facilities, playgrounds, type of roads in the vicinity and presence of water nearby. The study also noted that different types of user groups have different requirements of public open spaces, eg, some may find water features calming and attractive while parents of young children may see them as safety hazards.

In addition to the qualities and characteristics of the park, as noted earlier, social factors also play an important role in determining the accessibility and use of parks. ${ }^{28}$ These include feelings of community cohesion. ${ }^{30}$ Where feelings of social cohesion are absent, individuals may be less likely to use parks. This local sociocultural aspect of neighborhoods 
may adversely contribute to inequalities in health. Indeed, this may account for some subpopulation variations in green space use, eg, where ethnic and minority groups may be less likely to use green spaces. ${ }^{31,36}$

\section{Mechanisms of action and revealed functionality Limitations of the evidence base}

Many studies have explored the features and characteristics of urban green spaces that are associated with positive health benefits. However, the evidence for these links is weak, inconsistent, and occasionally contradictory owing to the heterogeneity of the studies undertaken. ${ }^{15,37,39,40}$ In addition, there are limitations affecting the observational, ecological, and cross-sectional studies that have been carried out, ie, multiple confounding factors and the long time lag between exposure to green space and manifestation of effects. ${ }^{13,41}$

We have previously reported on the other limitations of many studies, such as failure to use a comparison group, use of inappropriate measures, selection bias, short follow-up periods, and failure to account for the fact that use of urban green space may be biased toward physically active groups rather than the population as a whole. Many studies found associations between health indicators and urban green space that were null or not statistically significant. ${ }^{13}$ A recent systematic review found that studies utilizing objective physical activity measures such as pedometers and those examining direct measures of obesity were, respectively, $18 \%$ and $6.2 \%$ less likely to find a beneficial relationship. ${ }^{42}$ There is also the issue of ecological fallacy, ie, not everyone who lives in a leafy suburb with good access to urban green space will necessarily derive a health benefit. ${ }^{14,43}$

Consequently, there is currently insufficient robust evidence to prove a causal relationship between urban green space and health benefits. While finding objective measures of benefit has been challenging with mixed results, the self-reported benefits of green spaces have tended to be much more consistent. ${ }^{15}$

\section{Mechanism of action for the health benefits of urban green space}

So why are there such mixed findings in the literature? Part of the issue may be how previous studies have explored the associations between health and green space. Several studies have sought to identify "features" and "characteristics" of urban green spaces that are linked with health outcomes, eg, hygiene, size, esthetic appeal, and facilities. ${ }^{28}$ However, this approach makes an assumption of direct causality between the features of an urban green space and outcomes. Once again, our previous review found that it was difficult to ascertain to what extent the environmental attributes of an urban green space were responsible for any health benefits seen. ${ }^{13}$

In reality, the relationship is more likely to be complex, multifactorial, and prone to considerable confounding. ${ }^{13}$ Health outcomes are more likely to be directly linked to the activities that are undertaken in the urban green space, ie, based on its functionality (Figure 1). In other words, it is likely that the health benefits accrued are a result of use of urban green spaces and not just from their presence. One research priority therefore would be to study and unravel the possible mechanisms that lead to health benefits, and reveal the functionality of the space that is health-promoting.

\section{Implications for research and practice}

Assuming functionality is linked to health outcomes, the different uses of urban green space is likely to yield different health benefits. For example, based on the studies reviewed thus far, eg, social benefits such as the reduction of social isolation is predicated on social contact happening in an urban green space. That space may have to be situated in the right locality, carry some social meaning for the neighborhood, and its user groups permit or facilitate social interactions to occur. ${ }^{30}$ The observation that some minority groups do not use certain green spaces indicates that such spaces may be contested spaces that limit accessibility and acceptability to certain groups only. Consequently, modifications of the physical environment alone may be insufficient to promote physical activity if there are significant psychosocial processes at play. These social ties, social networks, and social interactions may differ quite considerably between affluent and more deprived neighborhoods. Therefore, concomitant modifications of the social environment may be required. ${ }^{44}$ In addition, there is also a need to identify what health outcomes are sought, what activities in urban green spaces contribute to these outcomes, and in turn identify what features of an urban green space would encourage such activities. A blunderbuss approach to development of urban green spaces may not translate into the desired health outcomes.

The weaknesses of the evidence base to date highlight the need for more rigorous scientific research to determine whether altering the built environment will result in increased levels of physical activity and decreased obesity rates. More research attention needs to be paid to these relationships, building on advances in research design and analytical approaches. 


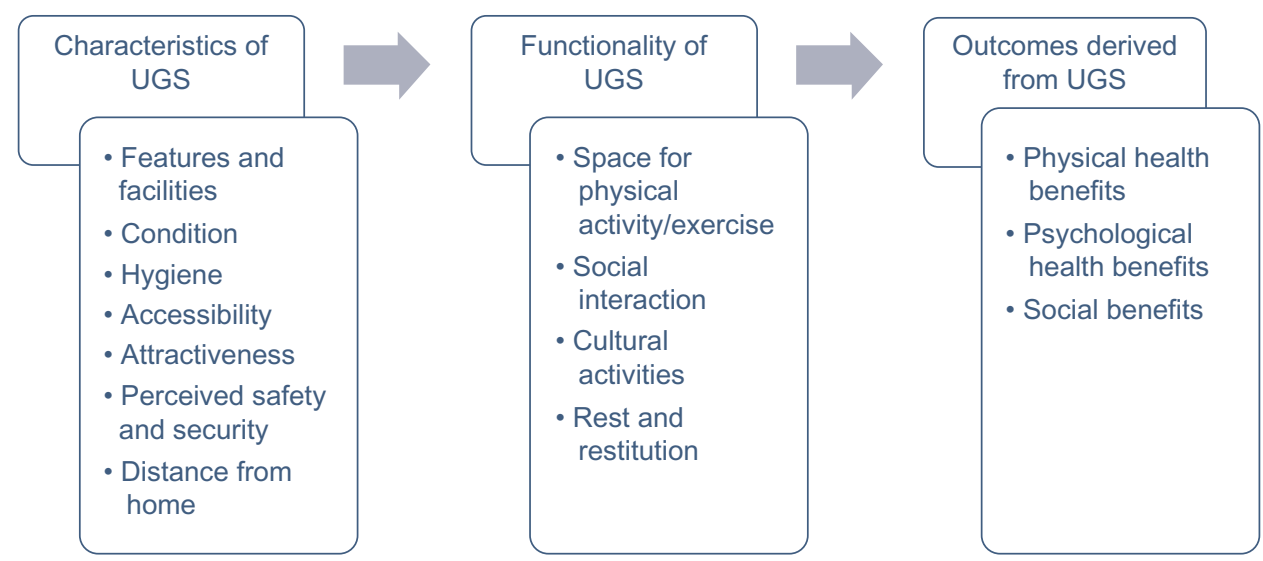

Figure I Relationship between urban green space characteristics, functionality, and outcomes. Abbreviation: UGS, urban green space.

\section{Potential threats to urban green space and possible solutions}

Urban green spaces will inevitably be threatened in an environment where urban space is limited and there is a relative shortage of housing and land available for development. Urban green space costs money to maintain. Where green space is perceived as being run down, it may be at greater risk of being developed rather than refurbished. Resource constraints and reductions in public spending are likely to have a disproportionate impact on urban green space as it has to compete with other public services that have higher priority or political sanction, as has happened in the UK. ${ }^{45}$ In the absence of a robust scientific basis for the health benefits of urban green space, it is difficult to make the case for allocating scarce public health resources to an endeavor for which there is limited information and which could be perceived as simply a "fad".

Furthermore, urban green space planning cannot be seen in isolation from other local government priorities such as transport and housing. Efforts to engineer health-promoting towns and cities are often beleaguered by poor integration between planning, transport, housing, and health policies. Training, communication, and an understanding of the levers for change are essential prerequisites for urban planners to be able to address the joint concerns of planning and health, as embodied in green space planning.

Another potential threat to public green space is where the space is available but access to it is restricted. This is often seen where urban land is redeveloped for housing and green space is provided but is only accessible to residents. This is an attractive approach for developers, as the "exclusive" green space may increase the retail value of the property; however, such approaches inevitably increase inequities in access. Similarly, urban green space initiatives to make more deprived neighborhoods healthier and more attractive can drive up property values and displace the residents for whom the initiatives were designed to be of benefit. ${ }^{46}$

\section{Conclusion and perspectives}

The literature to date has several key implications for urban planning. Firstly, urban planning can and should have a public health component in view of the purported health benefits. Improving the accessibility is likely to lead to greater use of urban green space. In practice, this could take the form of health impact assessments of urban developments. ${ }^{21}$ If urban green space planning is part of a wider health promotion policy, active marketing and promotion of its use is likely to be needed, especially where levels of provision or preexisting use is insufficient. Radical shifts in current approaches to urban design may be called for.

Secondly, residents use urban green spaces in a variety of ways. Therefore, it is important to understand how the green space may be used and what the needs of residents are. ${ }^{29,30} \mathrm{In}$ order to enable urban development to better match local needs and values, public engagement in the planning and design process is key. ${ }^{7}$ Furthermore, if urban greening programs are carried out without due attention to the form these green spaces are to take or to related aspects such as city transport strategies, there may be no benefit in terms of population health. ${ }^{43}$

There remain several unknowns. Firstly, how much urban green space is needed, ie, what is the optimal green space ratio ${ }^{7}$ Secondly, what enhancements are required and what degree of features are needed to facilitate usage and the benefits accrued from urban green space? ${ }^{21}$ How do we encourage its use?

Finally, there is a need for further economic work to calculate the cost to benefit/utility of urban green space. ${ }^{31}$ 
This is challenging in view of the multiplicity of uses and potential co-benefits accrued, as well as difficulties quantifying both the costs and attributable benefits. In view of the multiplicity of purposes served by urban green spaces, as well as the range of benefits to urban areas, they are more than a peripheral nicety and are a key aspect of urban planning and design.

\section{Disclosure}

The authors report no conflicts of interest in this work.

\section{References}

1. Public Health England Obesity. Adult weight data factsheet. Public Health England; 2014. Available from: http://www.noo.org.uk/ securefiles/150708_0057//AdultWeight_Aug2014_v2.pdf. Accessed May 15, 2015.

2. Ogden CL, Carroll MD, Kit BK, et al. Prevalence of childhood and adult obesity in the United States, 2011-2012. JAMA. 2014;311(8): 806-814.

3. Ferrari AJ, Somerville AJ, Baxter AJ, et al. Global variation in the prevalence and incidence of major depressive disorder: a systematic review of the epidemiological literature. Psychol Med. 2013;43(3):471-481.

4. Barton H, Grant M. Urban planning for healthy cities. J Urban Health. 2013;90(1):129-141.

5. Barton J, Pretty J. What is the best dose of nature and green exercise for improving mental health? A multi-study analysis. Environ Sci Technol. 2010;44(10):3947-3955.

6. Van Leeuwen E, Nijkamp P, de Noronha Vaz T. The multifunctional use of urban greenspace. Int J Agr Sustain. 2010;8(1-2):20-25.

7. Haq SM. Urban green spaces and an integrative approach to sustainable environment. J Environ Protect. 2011;2(5):601-608.

8. Branas CC, Cheney RA, MacDonald JM, et al. A difference-in-differences analysis of health, safety, and greening vacant urban space. Am J Epidemiol. 2011;174(11):1296-1306.

9. Strohbach MW, Arnold E, Haase D. The carbon footprint of urban green space - a life cycle approach. Landscape Urban Plan. 2012;104(2): 220-229.

10. Pataki DE, Carreiro MM, Cherrier J, et al. Coupling biogeochemical cycles in urban environments: ecosystem services, green solutions, and misconceptions. Front Ecol Environ. 2011;9(1):27-36.

11. Roy S, Byrne J, Pickering C. A systematic quantitative review of urban tree benefits, costs, and assessment methods across cities in different climatic zones. Urban For Urban Gree. 2012;11(4):351-363.

12. Young RF. Managing municipal green space for ecosystem services. Urban For Urban Gree. 2010;9(4):313-321.

13. Lee AC, Maheswaran R. The health benefits of urban green spaces: a review of the evidence. J Public Health. 2011;33(2):212-222.

14. Mitchell R, Astell-Burt T, Richardson EA. A comparison of green space indicators for epidemiological research. J Epidemiol Community Health. 2011;65(10):853-858.

15. Richardson EA, Mitchell R. Gender differences in relationships between urban green space and health in the United Kingdom. Soc Sci Med. 2010;71(3):568-575.

16. Mytton OT, Townsend N, Rutter H, et al. Green space and physical activity: an observational study using health survey for England data. Health Place. 2012;18(5):1034-1041.

17. Macintyre S, Macdonald L, Ellaway A. Do poorer people have poorer access to local resources and facilities? The distribution of local resources by area deprivation in Glasgow, Scotland. Soc Sci Med. 2008; 67(6):900-914.

18. Lachowycz K, Jones AP, Page AS, et al. What can global positioning systems tell us about the contribution of different types of urban greenspace to children's physical activity? Health Place. 2012;18(3): $586-594$.
19. Maas J, Verheij RA, Groenewegen PP, et al. Green space, urbanity, and health: how strong is the relation? J Epidemiol Community Health. 2006;60(7):587-592.

20. Coombes E, Jones AP, Hillsdon M. The relationship of physical activity and overweight to objectively measured green space accessibility and use. Soc Sci Med. 2010;70(6):816-822.

21. Durand CP, Andalib M, Dunton GF, et al. A systematic review of built environment factors related to physical activity and obesity risk: implications for smart growth urban planning. Obes Rev. 2011;12(5): e173-e182.

22. Grazuleviciene R, Vencloviene J, Kubilius R, et al. The effect of park and urban environments on coronary artery disease patients: a randomized trial. BioMed Res Int. 2008;2008:403012.

23. Astell-Burt T, Feng X, Kolt GS. Is neighborhood green space associated with a lower risk of type 2 diabetes? Evidence from 267,072 Australians. Diabetes Care. 2014;37:197-201.

24. Hartig T, van den Berg AE, Hagerhall CM, et al. Health benefits of nature experience: psychological, social and cultural processes. In: Nilsson K, Sangster M, Gallis C, et al, editors. Forests, Trees and Human Health. Rotterdam, The Netherlands: Springer; 2011.

25. van den Berg AE, Maas J, Verheij RA, et al. Green space as a buffer between stressful life events and health. Soc Sci Med. 2010;70(8): 1203-1210.

26. Nutsford D, Pearson AL, Kingham S. An ecological study investigating the association between access to urban green space and mental health. Public Health. 2013;127(11):1005-1011.

27. Sugiyama T, Thompson CW. Associations between characteristics of neighbourhood open space and older people's walking. Urban For Urban Gree. 2008;7(10):41-51.

28. Bedimo-Rung AL, Mowen AJ, Cohen DA. The significance of parks to physical activity and public health: a conceptual model. Am J Prev Med. 2005;28(2):159-168.

29. Lo AY, Jim CY. Differential community effects on perception and use of urban greenspaces. Cities. 2010;27(6):430-442.

30. Seaman PJ, Jones R, Ellaway A. It's not just about the park, it's about integration too: why people choose to use or not use urban greenspaces. Int J Behav Nutr Phys Act. 2010;7:78.

31. Schipperijn J, Ekholm O, Stigsdotter UK, et al. Factors influencing the use of green space: results from a Danish national representative survey. Landscape Urban Plan. 2010;95(3):130-137.

32. Peschardt KK, Schipperijn J, Stigsdotter UK. Use of small public urban green spaces (SPUGS). Urban For Urban Gree. 2012;11(3):235-244.

33. Peschardt KK, Stigsdotter UK. Associations between park characteristics and perceived restorativeness of small public urban green spaces. Landscape Urban Plan. 2013;112:26-39.

34. Dinnie E, Brown KM, Morris S. Community, cooperation and conflict: negotiating the social well-being benefits of urban greenspace experiences. Landscape Urban Plan. 2013;112:1-9.

35. Kessel A, Green J, Pinder R, et al. Multidisciplinary research in public health: a case study of research on access to green space. Public Health. 2009;123(1):32-38.

36. van Dillen SM, de Vries S, Groenewegen PP, et al. Greenspace in urban neighbourhoods and residents' health: adding quality to quantity. J Epidemiol Community Health. 2012;66(6):e8.

37. Rosso AL, Auchincloss AH, Michael YL. The urban built environment and mobility in older adults: a comprehensive review. J Aging Res. 2011;2011:816106.

38. Francis J, Wood LJ, Knuiman M, et al. Quality or quantity? Exploring the relationship between public open space attributes and mental health in Perth, Western Australia. Soc Sci Med. 2012;74(10):1570-1577.

39. Richardson E, Pearce J, Mitchell R, et al. The association between green space and cause-specific mortality in urban New Zealand: an ecological analysis of green space utility. BMC Public Health. 2010;10(1):240.

40. Thompson CJ, Boddy K, Stein K, et al. Does participating in physical activity in outdoor natural environments have a greater effect on physical and mental wellbeing than physical activity indoors? A systematic review. Environ Sci Technol. 2011;45(5):1761-1772. 
41. Lachowycz K, Jones A. Greenspace and obesity: a systematic review of the evidence. Obes Rev. 2011;12(5):e183-e189.

42. Ferdinand AO, Sen B, Rahurkar S, Engler S, Menachemi N. The relationship between built environments and physical activity: a systematic review. Am J Public Health. 2012;102(10):e7-e13.

43. Richardson EA, Mitchell R, Hartig T, de Vries S, Astell-Burt T, Frumkin H. Green cities and health: a question of scale? J Epidemiol Community Health. 2012;66(2):160-165.

44. Oka M. Toward designing an environment to promote physical activity. Landscape J. 2011;30(2):280-298.
45. Allender S, Gleeson E, Crammond B, et al. Policy change to create supportive environments for physical activity and healthy eating: which options are the most realistic for local government? Health Promot Int. 2012;27(2):261-274.

46. Wolch JR, Byrne J, Newell JP. Urban green space, public health, and environmental justice: the challenge of making cities 'just green enough'. Landscape Urban Plan. 2014;125:234-244.

\section{Publish your work in this journal}

Risk Management and Healthcare Policy is an international, peerreviewed, open access journal focusing on all aspects of public health, policy, and preventative measures to promote good health and improve morbidity and mortality in the population. The journal welcomes submitted papers covering original research, basic science, clinical \& epidemio- logical studies, reviews and evaluations, guidelines, expert opinion and commentary, case reports and extended reports. The manuscript management system is completely online and includes a very quick and fair peerreview system, which is all easy to use. Visit http://www.dovepress.com/ testimonials.php to read real quotes from published authors.

Submit your manuscript here: http://www.dovepress.com/risk-management-and-healthcare-policy-journal 